\title{
THE INFLUENCE OF THE COLLAPSIBILITY OF VEINS ON VENOUS PRESSURE, INCLUDING A NEW PROCEDURE FOR MEASURING TISSUE PRESSURE
}

\author{
By HENRY W. RYDER, WILLIAM E. MOLLE, AND EUGENE B. FERRIS, JR. \\ (From the Department of Internal Medicine, Cincinnati General Hospital, and the College of Medicine, \\ University of Cincinnati, Cincinnati)
}

(Received for publication October 21, 1943)

The study of the venous pressure by the direct method of Moritz and von Tabora (1) has been of great value in the diagnosis and physiological understanding of heart failure and a number of other conditions. Provided a certain technique in measurement, as outlined by Lyons, Kennedy, and Burwell (2), is observed, it is commonly assumed that the arm venous pressure is a function of the atrial pressure, since the vein is a tube connecting the antecubital space with the heart. It is our purpose to show that the peculiar nature of this tube, in that it is easily collapsible, places important restrictions on this interpretation.

The critical experiment in this regard is the classical phenomenon, studied by many observers, of the behavior of the venous pressure as the arm is raised (Fig. 7). When the pressure is referred to the heart level, the pressure is constant until the arm reaches a certain point, and then rises equally with further elevation. When the pressure is referred to the vein level, the pressure falls until this same point is reached, and then remains constant. Observation indicates that below this point, the vein is distended, and at and above this point, the vein is collapsed.

It is with the full interpretation of this phenomenon that this paper deals. It is our purpose to show that when the vein is distended, it does measure the central venous pressure, and that when it is collapsed, it is completely independent of central influences and measures only the tissue pressure about the vein at the point of measurement. This will be done by showing, first, that a collapsible tube behaves in this way; second, that an isolated segment of vein has the properties of a collapsible tube; and third, that the vein behaves in vivo just as it does in vitro.

\section{MATERIALS AND METHODS}

Static experiments. The static experiments were done on a rubber glove and on excised veins.

The distensibility curves of a rubber glove were obtained as follows. A glass tube was tied into the rubber glove, and bent in such a way that negative as well as positive pressures could be read, and a side tube was connected so that increments of fluid could be added. The rubber glove was stuffed into a $250 \mathrm{cc}$. graduate, mounted horizontally, and closed at the open end by a two-holed rubber stopper. A glass tube was bent in the shape of a $U$, and so connected to the graduate that the pressure in the graduate could be read by measuring the difference in height of the water columns in the $U$ tube. A side arm was added for applying a desired pressure and readjusting the pressure after increments of water were added to the glove.

An internal mammary vein which was apparently normal was obtained 12 hours post-mortem. It was mounted in an analogous fashion to the rubber glove, but with refinements such that increments of volume change could be measured after adding fluid from a micro-burette, accurate to $\pm 0.005 \mathrm{cc}$. The pressure changes were recorded in a capillary of such cross-sectional area that 0.01 cc. of fluid occupied $2.4 \mathrm{~cm}$. of its length. Pressures were read to the nearest millimeter of water, and corrections were made for the volume change in the manometer. All connections were glass to glass, or by pressure tubing. The vein was mounted horizontally, and placed under very slight longitudinal tension by fitting in two small copper wires. This was necessary to allow saline to enter the vein and be distributed throughout its length; otherwise, its walls stuck together.

A grossly normal common iliac vein was obtained 8 hours post-mortem. It was mounted in a fashion similar to the internal mammary vein, except that the volume was read only to an accuracy of $0.1 \mathrm{cc}$. Like the rubber glove, it was enclosed in a graduate so as to permit the control and measurement of ambient pressure variations.

Dynamic experiments. The dynamic studies were done on a thin walled latex tube and a common iliac vein.

The model consisted of a latex tube, $5.36 \mathrm{~cm}$. in circumference, with a wall, $0.030 \mathrm{~cm}$. in thickness, mounted at about $30^{\circ}$ to the horizontal. It was secured at each end around glass tubes of the same internal circumference. The ends of the glass tube were $34.8 \mathrm{~cm}$. apart. Tap 
water was admitted at the higher end at the rate of $243 \mathrm{cc}$. per minute by pressure tubing. The lower end was connected to rubber tubing, the outflow level of which could be varied with respect to the level of the latex tube.

A glass capillary was led into the center of the latex tube from one end, and connected to a water manometer. The latex tube, so arranged, was mounted inside a glass cylinder, closed at both ends by rubber stoppers, through which were passed the glass tubes on which the latex tube was mounted. The pressure in this air-filled cylinder was measured by the difference in height of the water in the two arms of a U-tube, one end of which was connected to the cylinder, and the other to the outside air. A syringe and needle arrangement permitted the maintenance of a desired pressure.

The model made possible the study of the pressure changes inside the latex tube at given volume flows of water, with different external pressures, with varying outflow levels, with the tube raised or lowered, and inspection of the visible changes in the shape of the latex tube under these conditions.

The analogous parts of the in vivo system are the vein to the latex tube, the cuff about the arm to the closed air space about the tube, the atrial level to an arbitrary reference point, and the atrial pressure to the distance of the outflow level above this arbitrary reference point. To avoid confusing terminology, the different parts of the model will be named after the analogous parts of the in vivo system. With reference to the arbitrary reference point ("atrial level"), the outflow level will be called the "atrial" pressure, the pressure in the tube, the "central venous pressure," and the level of the catheter tip in the tube, the "vein" level. With reference to the "vein" level, the pressure in the tube will be called the "local venous pressure."

If the pressure readings are considered to be in absolute units, so that the heights of the fluid columns in the manometers can be read as pressures, then the above definitions establish a relation between the pressure and the two reference points ("vein level" and "atrial level") as follows: $V L=C V P-L V P$, where $V L$ is the vein level, $C V P$ is the central venous pressure (height of fluid column above atrial level), and $L V P$ is the local venous pressure (height of fluid column above vein level). Because of this relation, the observed values are plotted on triaxial coordinates, in order that the relation of each pressure reading to the two reference points can be most advantageously shown.

In vivo studies. The in vivo studies were done on a variety of subjects, in all stages of health and disease. None had obvious local disease of the veins.

The venous pressures were determined by the direct method of Moritz and von Tabora (1), as modified by Lyons, Kennedy, and Burwell (2), with the patients lying supine. A minor but convenient modification in their

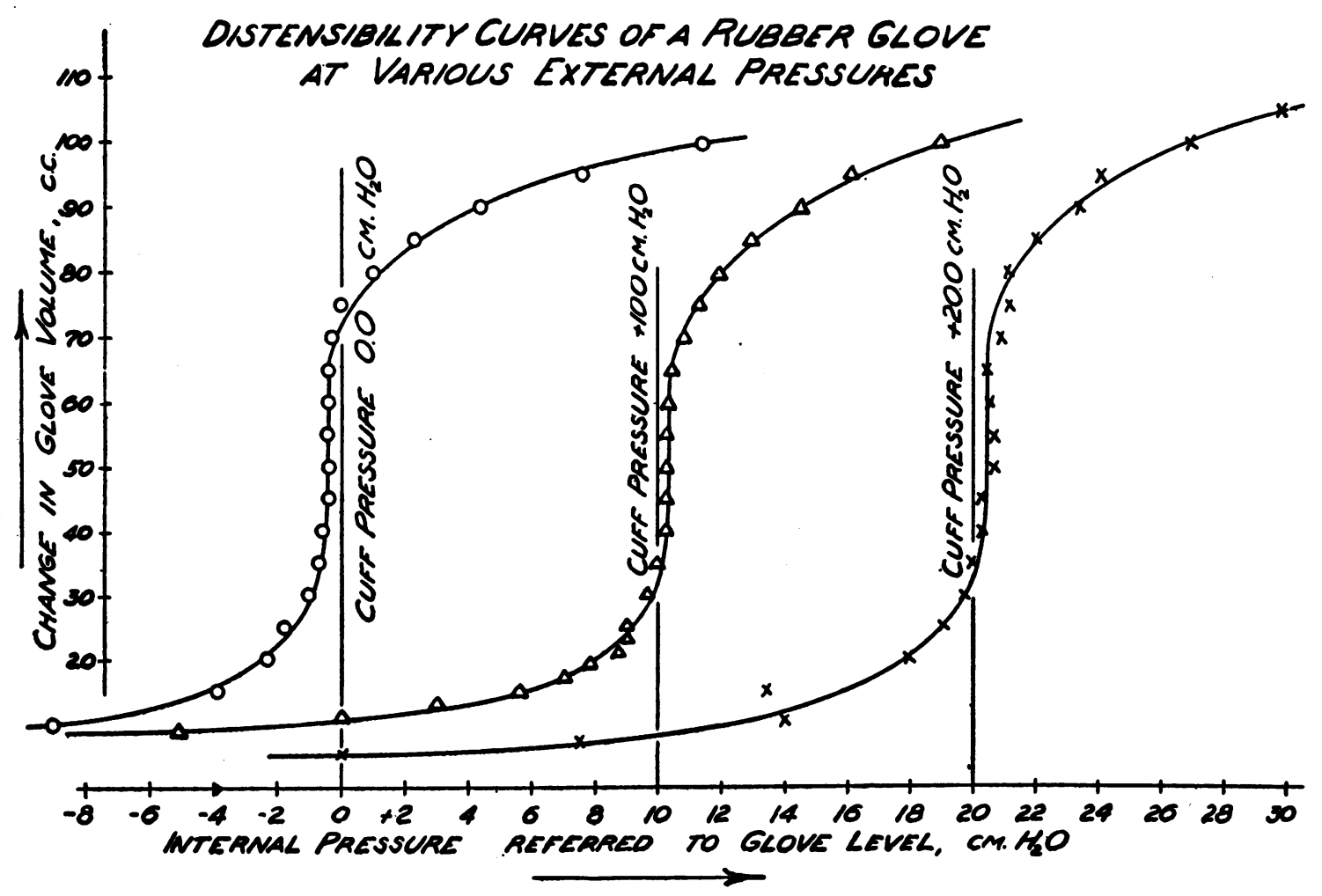

Fig. 1. Distensibility Curves of a Rubber Glove at Various External Pressures

Considerable increments of fluid may be added to the glove without change in internal pressure, within certain limits of volume change of the glove. The internal pressure is equal to the external pressure during this phase. 


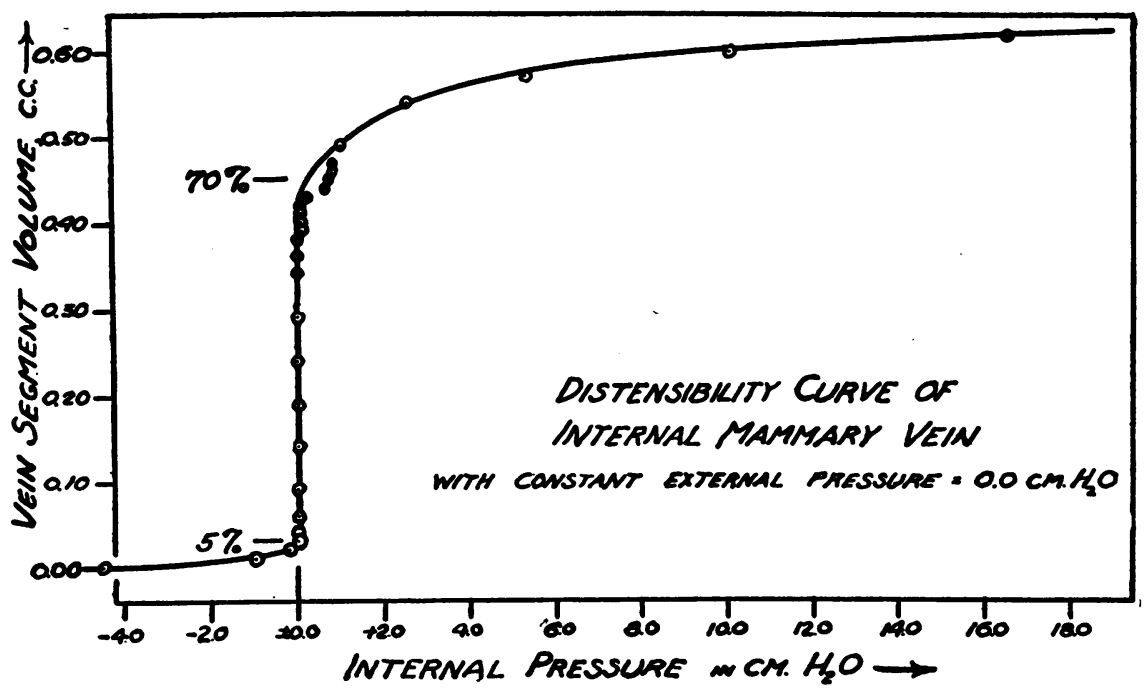

Fig. 2. Distensibitity Curve of an Internal mammary Vein Segment

For a wide range of volume change, the internal pressure reflects the ambient pressure.

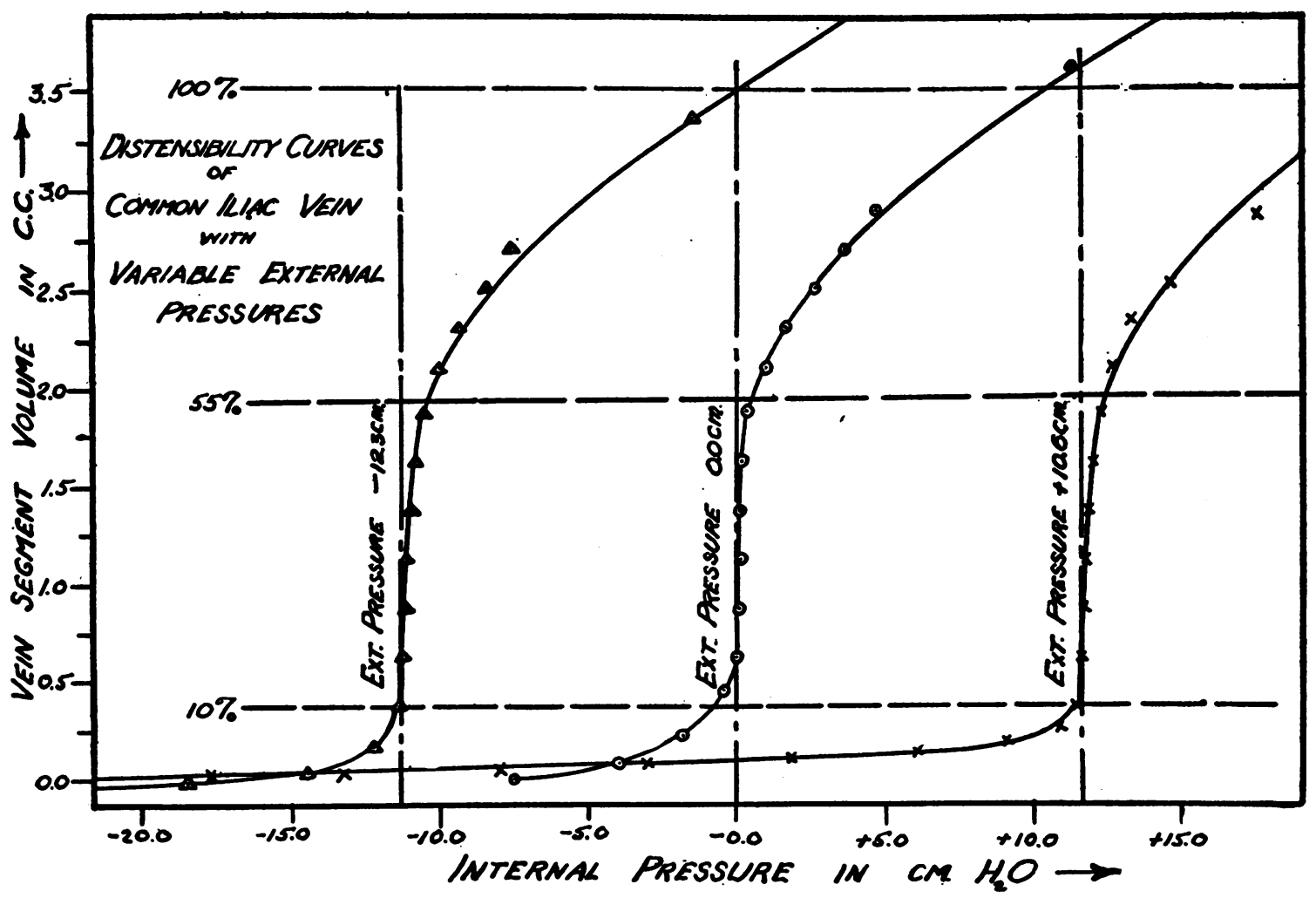

Fig. 3. Distensibility Curve of a Common Iliac Vein Segment

For a range less wide than in the smaller vein, the internal pressure reflects the ambient pressure. 
procedure was the method of establishing the manometer level of the atrium. We measured the antero-posterior chest diameter from the angle of Louis to the spine of the fourth thoracic vertebra with obstetrical calipers, and then by means of a spirit level related the manometer to the angle of Louis so that the manometer zero (atrial level) was $10 \mathrm{~cm}$. above the spine of the fourth thoracic vertebra. In some of the studies, a vein on the dorsum of the forearm was used instead of the antecubital vein. Normal saline was usually used without an anticoagulant. The pressure readings were corrected for capillarity when necessary. The vein levels were determined by feeling the tip of the needle in the vein, and leveling accordingly. Particularly when a cuff is in place over the needle tip, the error in leveling may be as great as $1 \mathrm{~cm}$.

\section{OBSERVATIONS}

Static properties of collapsible tubes and veins. When increments of volume are added to a thin walled bladder, the pressure-volume relations follow a sigmoid curve, with a long vertical rise of volume change without measurable pressure change, representing a state of free distensibility ${ }^{1}$ (Figure 1). If the total capacity of the bladder

1 The terms "free distensibility" and "free collapsibility" are used interchangeably throughout this paper, and are considered to denote the range of free volume change. (or segment) is arbitrarily taken as the volume change effected by internal pressures from $10 \mathrm{~cm}$. water below to $10 \mathrm{~cm}$. above the ambient (surrounding) pressure, the range of free disterisibility relative to total capacity is wide and becomes wider the thinner the bladder wall. In this range of free distensibility, the internal pressure is equal to the ambient pressure. Isolated vein segments behave in the same way and likewise, their range of free distensibility depends upon the properties of the vein wall (Figures 2 and 3), becoming less as the thickness of the wall increases.

Dynamic properties of collapsible tubes and veins. At volume flows just below those which induce bumping, the latex tube is found to have properties analogous to those of the bladder, studied under static conditions. The tube is collapsed when it is some distance above the outflow level, and distended when it is below the outflow level. When the tube is collapsed, it mirrors exactly the ambient pressure, as measured in a cuff about the tube; and it is quite independent of any level at which the outflow is set, provided the outflow level is not high enough

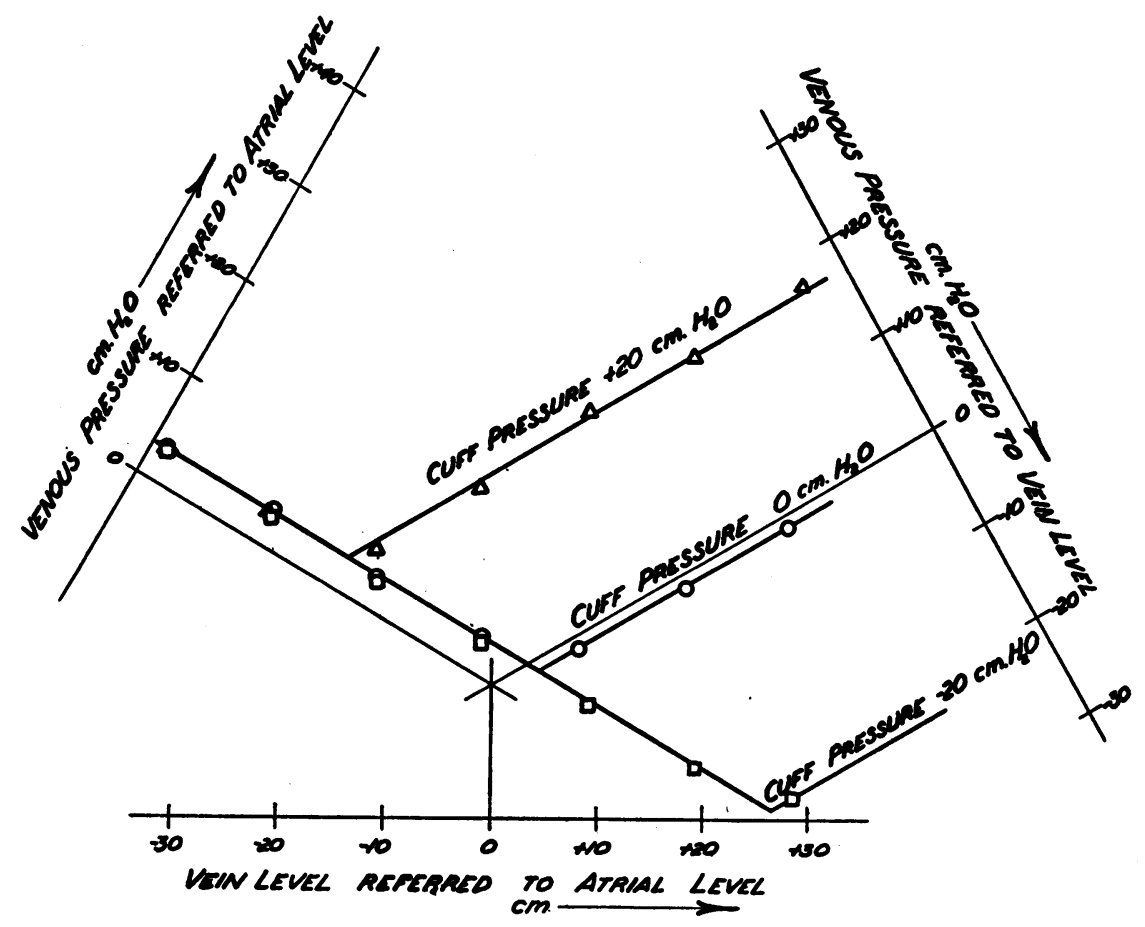

Fig 4. Dynamic Model Experiments

For description of terms, see text under the description of the model. The pressure inside the tube, "venous pressure," is constant in reference to the "atrial level" when the tube is distended by the "atrial pressure." As soon as the tube is collapsed by increasing the external cuff (ambient) pressure, the internal pressure mirrors this pressure, and is independent of the "atrial pressure." 


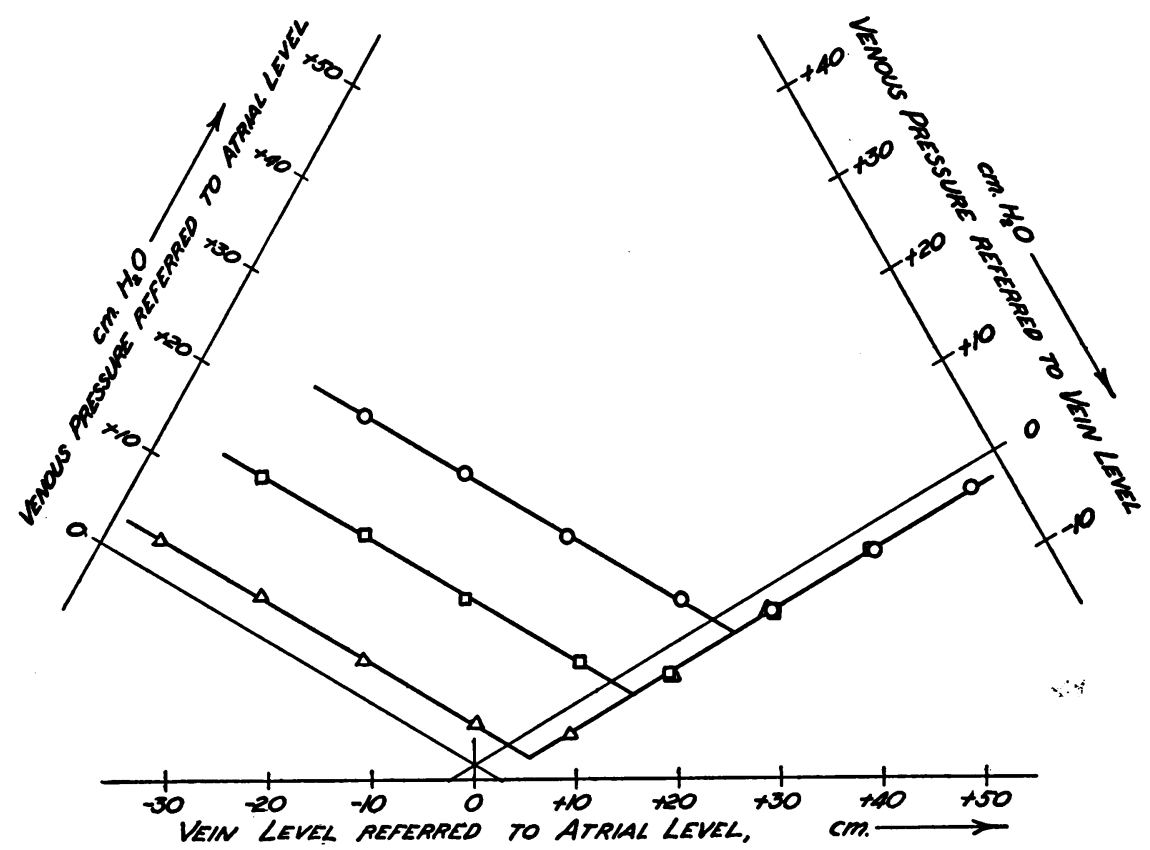

Fig. 5. Dynamic Model Experiments

When the "atrial pressure" is changed by changing the outflow level, the pressure in the tube reflects the change in the "atrial pressure," remaining constant at the "atrial pressure" as long as the tube is distended, no matter what the "vein level" is. The internal pressure is independent of the "atrial pressure" as soon as the "vein" collapses when sufficiently elevated.

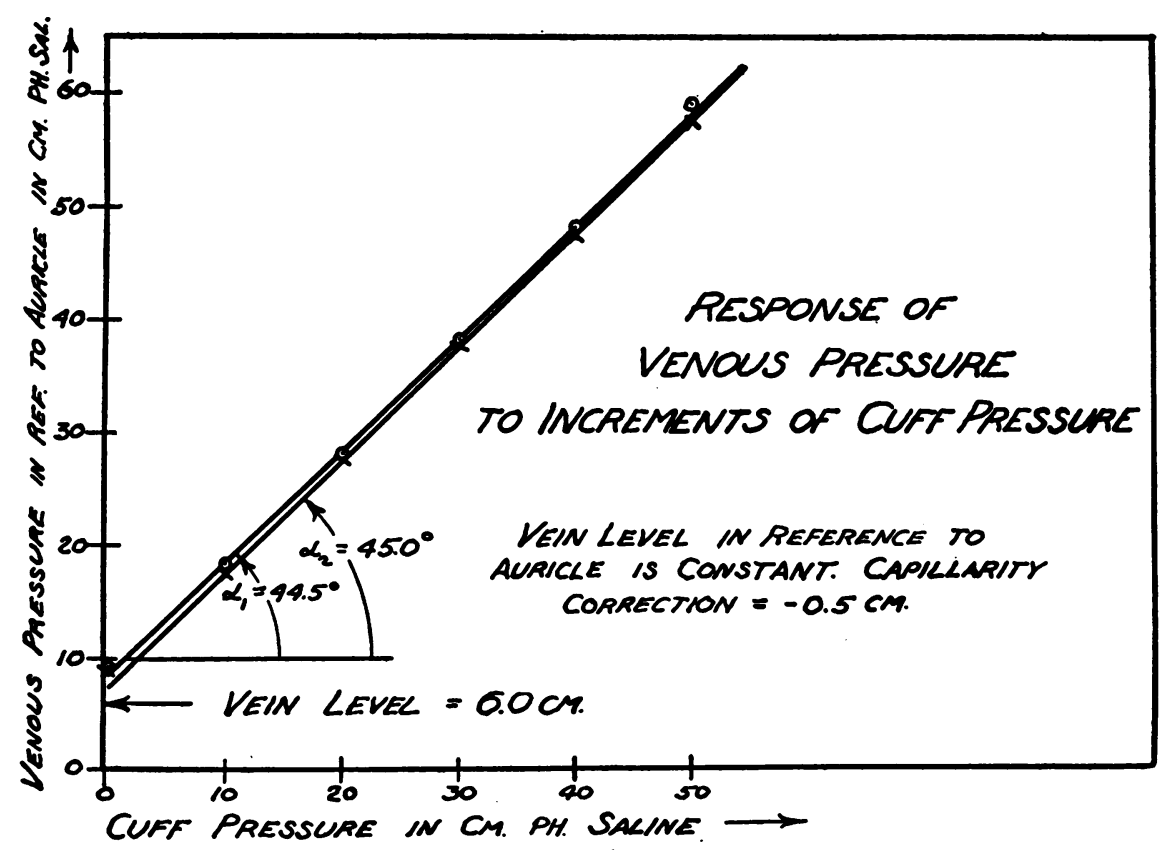

Fig. 6. Complete Transmission of Cuff Pressure to a Forearm Vein, in Vivo

The cuff was placed about the forearm vein with the vein at the indicated level, and the cuff then inflated to $50 \mathrm{~cm}$. of pressure. The venous pressure was recorded at that cuff pressure, and at successive $10 \mathrm{~cm}$. decrements of cuff pressure. After the first run, denoted by circles, the cuff was slightly readjusted, and the second curve obtained. The applied cuff pressure was completely transmitted the second run. 
to distend the tube and the volume flow is in the proper range. When the tube is distended, its internal pressure equals the level of the outflow tube and is quite independent of the ambient pressure changes (Figures 4 and 5).

The isolated vein behaves in quite the same way.

Veins in vivo. The procedures on arm veins in vivo are anlogous to the above experiments. When the vein is elevated to the point of collapse, and a cuff is placed around the arm and overlying the vein, increments of pressure added to the cuff are exactly transmitted to the lumen (Figure 6). When the vein is distended by holding it below the body level, increments of cuff pressure do not affect the lumen pressure at all, until the cuff pressure exceeds the lumen pressure.

A slight modification in the procedure is necessary to show conveniently the dependence of the pressure in the distended vein on more central influences. When the arm of any indi- vidual is raised from a position of maximal depression to one of maximal elevation, and the venous pressure is measured continuously, the venous pressure curves, plotted in reference to the atrial and vein levels, are characteristic (Figure 7). The use of individuals with different central pressures (referred atrial pressure) changes the magnitude of the pressure but not the form of the curve (Figure 8). The application of arbitrary cuff pressures over the vein does not affect the venous pressure as long as the vein is distended, but does affect the pressure when the vein is collapsed, either by elevation or by a sufficiently high cuff pressure (Figure 9). Individuals with different central pressures show constant differences as long as their veins are distended (Figure 8). The veins in this experiment behave in vivo just as the tube does in vitro as the level of the tube is raised.

The effect of tissue pressure. The constant positive hydrostatic pressure difference between the local venous pressure and the vein level,

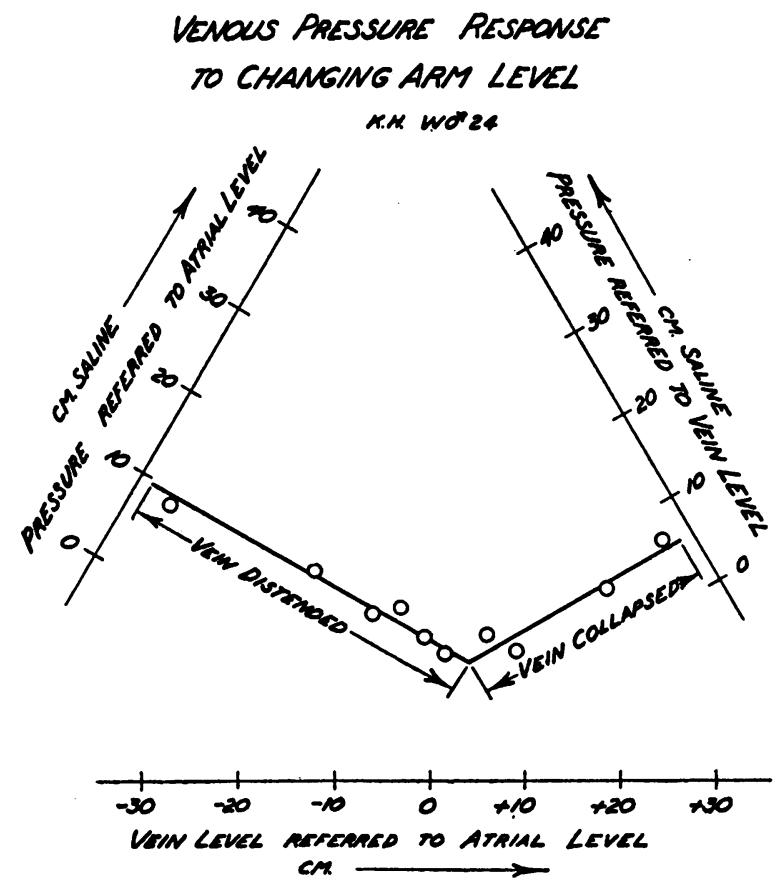

Fig. 7. Venous Pressure Response to Changing Arm level

As the arm is raised from a dependent position, beginning with the arm vein $27 \mathrm{~cm}$. below the atrial level, the vein remains distended and the pressure remains constant in reference to the atrial level, but falls in relation to the vein level, until a point $4 \mathrm{~cm}$. above the atrium is reached. At this point, the vein collapses, and above it, the pressure in reference to the vein level remains constant while the pressure in reference to the atrial level appears to rise. 


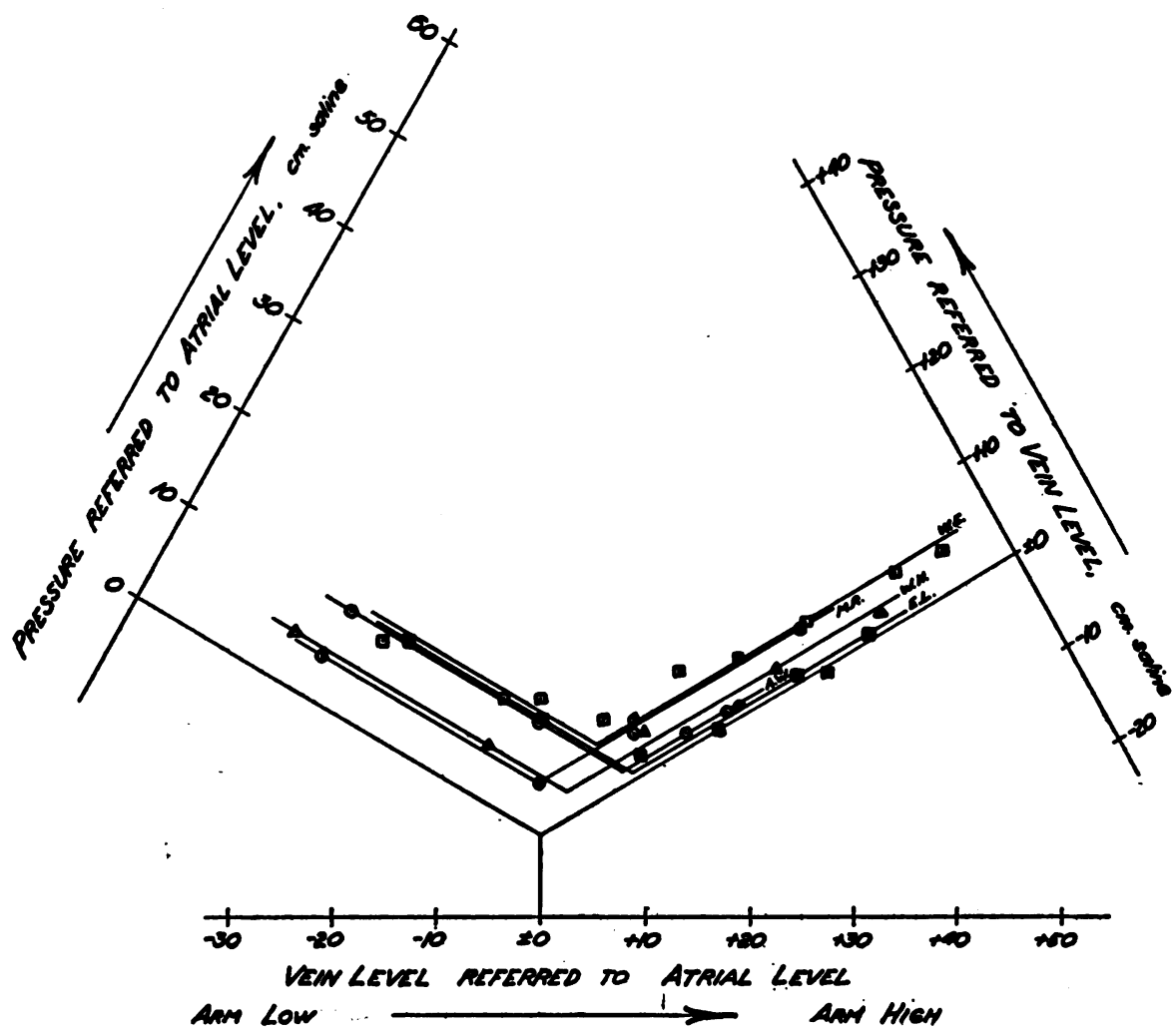

Fig. 8. Pressure Relations in Different Subjects

The pattern of the pressure changes is the same for all the individuals, but the pressure levels are characteristic for each individual.

when the vein is any distance above the point of collapse, is quite analogous to the local pressure in the collapsed rubber tube, which has been shown to be a function of the ambient external pressure. The fact that changes in cuff pressure are completely transmitted to the lumen of the vein (Figure 6) proves that under , these conditions the vein is freely collapsible, since the vein wall does not resist this complete transmission of pressure. If the tissue pressure is defined as the hydrostatic pressure exerted by the tissue on any point in the tissue, the residual pressure in the vein must then be exactly equal to the tissue pressure about the vein. ${ }^{2}$

2 If the local pressure in a collapsed vein is to be interpreted as being due solely to tissue pressure about the vein, measurable tonus in the vein wall must be absent, and the volume flow must be such that the vein is not collapsed beyond its range of free collapsibility; proof that both conditions obtain derives from the fact that under the conditions of the experiment the vein is freely collapsible.
In this connection, it is of interest to compare our observations on the tissue pressure, as measured in this way, with those of Burch and Sodeman, measured by determining the pressure at which fluid could be forced into the tissue (Table I). There is no significant difference between the means of the two groups. Considering that the individuals are different, the sites.

On the other hand, in the course of these studies we have been able to induce measurable spasm of large superficial arm veins and to relax this spasm at will (3), and we have observed certain collapsed veins (internal jugular) in vivo in which the local pressure was a function of external pressure (4), but not the sole function. It can be stated, first, that under ordinary circumstances the arm veins are free of measurable tonus and the flow through them is such that the veins cannot collapse beyond the free range of volume change, and hence the local pressure in the collapsed arm vein is a measure solely of tissue pressure; and second, that the presence of venous spasm can be detected by local observation and palpation because the spastic vein is small, round, and firm, in contrast to the flat, soft character of the limp collapsed vein. 


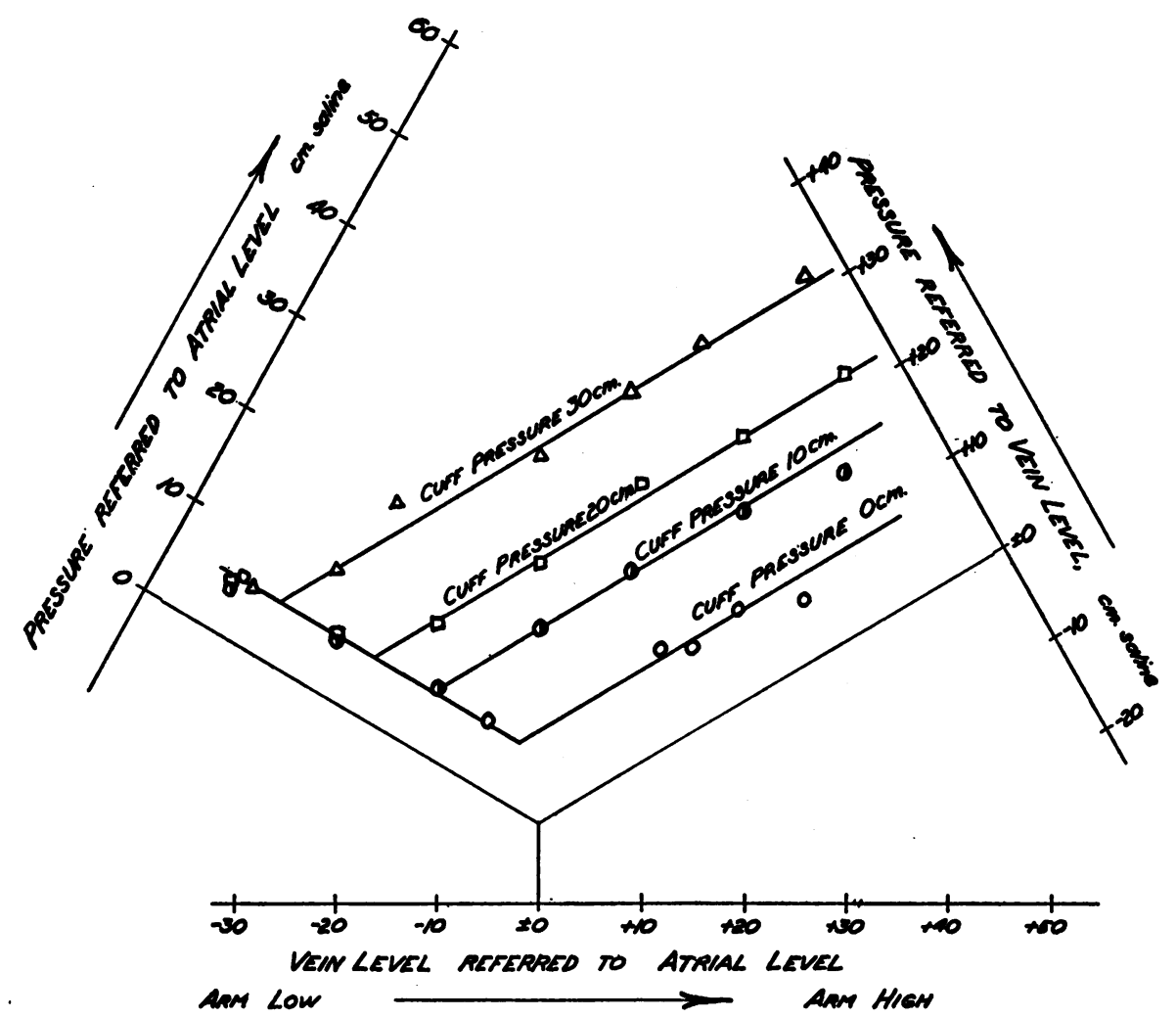

Fig. 9. Pressure Relations in the Same Subject with Different Cuff Pressures

The pattern is similar to the model (Figure 4). As long as the vein is distended, the pressure is constant when referred to the atrium, no matter what the vein level may be. When the vein is elevated sufficiently to collapse the vein, the internal pressure bears a constant relation to the particular cuff pressure applied at the time.

TABLE I

Values of tissue pressure as determined by two methods in two groups of normal individuals

There is no significant difference between the mean pressures for the two groups, as analyzed by "Students" " $t$ " test (Fisher (8)).

\begin{tabular}{|c|c|c|c|c|}
\hline $\begin{array}{l}\text { Burch and Sodeman- } \\
\text { Volar surface of } \\
\text { forearm }\end{array}$ & \multicolumn{4}{|c|}{ Presented method-Dorsum of forearm } \\
\hline $\begin{array}{c}m m . H \\
11 \\
29 \\
26 \\
23 \\
40 \\
19 \\
18 \\
17 \\
14 \\
39\end{array}$ & $\begin{array}{r}50 \\
10 \\
20 \\
10 \\
15 \\
20 \\
35 \\
65 \\
9 \\
11\end{array}$ & $\begin{array}{r}m m \\
40 \\
30 \\
85 \\
5 \\
10 \\
55 \\
105 \\
5 \\
14 \\
11\end{array}$ & $\begin{array}{r}730 \\
25 \\
30 \\
55 \\
50 \\
20 \\
40 \\
0 \\
5 \\
20 \\
25\end{array}$ & $\begin{array}{r}5 \\
0 \\
20 \\
30 \\
45 \\
10\end{array}$ \\
\hline Method & Mean & $\begin{array}{c}\text { S.E. } \\
\text { of } \\
\text { mean }\end{array}$ & $\begin{array}{l}\text { Mean } \\
\text { differ- } \\
\text { ence }\end{array}$ & $t$ \\
\hline $\begin{array}{l}\text { Burch and Sodeman } \\
\text { Presented }\end{array}$ & $\begin{array}{r}23.60 \\
27.60 \\
\text { ficanc }\end{array}$ & $\begin{array}{l} \pm 3.14 \\
\pm 3.98 \\
\text { None }\end{array}$ & 4.00 & 0.46 \\
\hline
\end{tabular}

for the measurement of the pressures were different, the forearm was above the atrial level with the patient supine, in our group, and the forearm at atrial level with the patient sitting, in their group, and that their method is subject to restrictions in interpretation as outlined by McMaster (5), the fact that the two groups of measurements are of the same order of magnitude, and that statistically there is no significant difference between them, suggests that each method is measuring some function of the same variable, namely, the tissue pressure.

\section{DISCUSSION}

We have shown that under physiological conditions of flow, peripheral veins are freely collapsible tubes, and therefore have peculiar properties. When they are collapsed, the internal pressure has nothing to do with the pressure in the atrium or the pressure in the vein at any point central to the point of measurement. 
This pressure can usually be shown to be equal to the tissue pressure around the vein by putting a cuff around the vein and demonstrating complete transmission of cuff pressure to the lumen. Furthermore, if the vein is in a freely collapsed state anywhere between the point of measurement and the atrium, even though it is distended at the point of measurement, the venous pressure is quite independent of the pressure in the atrium and depends instead on the pressure at the point of collapse.

The effect of the tissue pressure in collapsing a vein is additive to the effect of the level of the vein with respect to the central pressure head. The closer the vein level approaches the central pressure, the less the tissue pressure about the vein has to be in order to collapse it.

The importance of these characteristics in the interpretation of peripheral venous pressure is obvious. The influence of hydrostatic vein levels on peripheral pressure in veins has been emphasized by others $(2,6,7)$. The influence of tissue pressure, which, in most collapsed arm veins, is the sole determinant of the venous pressure, has not previously been recognized to our knowledge.

\section{SUMMARY}

1. Under static conditions in vitro, veins and rubber tubes are freely distensible within wide limits. Within this range of free distensibility, the internal pressure is equal to the external pressure.

2. Under dynamic conditions, veins and rubber tubes are still freely distensible within wide limits.

3. Veins in vivo show the same pressure responses to central and local influences that they do in vitro.

4. A human arm vein in vivo can be determined to be within its range of free distensibility by elevating the arm until the vein appears collapsed, and then demonstrating the complete transmission to its lumen of pressure applied externally by means of a cuff.
5. When a vein is collapsed to within its limits of free collapsibility, the internal pressure is equal to the surrounding tissue pressure.

6. These findings place certain important restrictions on the interpretation of the venous pressure as measured peripherally.

\section{CONCLUSIONS}

When arm veins are distended, the venous pressure measures central influences, and is independent of the local pressure around the veins.

When arm veins are collapsed, the venous pressure measures the tissue pressure that has collapsed them, and is independent of central influences.

The measurement of local venous pressure in freely collapsed veins offers a means of measuring tissue pressure under conditions of equilibrium.

\section{BIBLIOGRAPHY}

1. Moritz, F., and von Tabora, D., Über eine Methode, beim Menschen den Druck in oberflächlichen Venen exakt zu bestimmen. Deutsches Arch. f. klin. Med., 1910, 98, 475.

2. Lyons, R. H., Kennedy, J. A., and Burwell, C. S., The measurement of venous pressure by the direct method. Am. Heart J., 1938, 16, 675.

3. Molle, W. E., Ryder, H. W., and Ferris, E. B., Jr., Observations of measurable spasm in superficial veins. To be published.

4. Ryder, H. W., and Ferris, E. B., Jr., The response of internal jugular venous pressure to externally applied pressures as an index of cranial blood flow. To be published.

5. McMaster, P. D., An inquiry into the structural conditions affecting fluid transport in the interstitial tissue of the skin. J. Exper. Med., 1941, 74, 9.

6. von Recklinghausen, $H$., Unblutige Blutdruckmessung. Arch. f. Exp. Path. u. Pharmakol., 1906, 55, 375.

7. Holt, J. P., The measurement of venous pressure in man eliminating the hydrostatic factor. Am. J. Physiol., 1940, 130, 635.

8. Fisher, R.A., Statistical Methods for Research Workers. Oliver and Boyd, Edin., 5th ed., 1934, Sect. 21.02. 